\title{
Comparison of the 1D response analysis results of typical Hungarian soil types and the EC8 spectra based on a case study of seismic risk analysis in Győr
}

\author{
O. K. Kegyes-Brassai \& R. P. Ray \\ Department of Structural and Geotechnical Engineering, \\ Széchenyi István University, Hungary
}

\begin{abstract}
Assessment and management of earthquake risk requires several disciplines and different aspects to evaluate. Based on mathematical calculations, risk is the product of hazard and vulnerability. Considering earthquakes, the process of risk evaluation consists of several steps performed in parallel. One line of the research deals with the seismicity of the area by identifying potential sources, usually along fault systems, for probabilistic hazard assessment. The next step focuses on the simulation of strong ground motions for regional hazard assessment. Ground motion attenuation models are calibrated based on observed strong motion recordings and on theoretical computations taking into account realistic models for wave propagation as well as possible seismic source zones. Further research takes into account local site effects and will result in a microzonation for the evaluated area based on local soil conditions and field testing of the soil properties. Another line of research focuses on the built environment. This paper presents the case study for the city of Györ, focusing on the seismic hazard assessment of the typical soil types along the Danube. Extensive use of historical boring logs allowed for correlations and reasonable extrapolation of soil performance throughout the area. This has led to a pattern of soil layer distributions and delineates of several different soil zones for Györ. Compared to more simplified profile standards from building codes, it can be clearly seen that the different levels of hazard concerning Györ are apparent, even though almost all of the region belongs to soil category $\mathrm{C}$ based on EC8.
\end{abstract}

Keywords: response analysis, local site effect, soil profile, microzonation. 


\section{Introduction}

Seismologists and engineers divide the problem of seismic wave transmission into four stages: source, geologic path through rock layers, near surface path through soil and surficial rock layers, and interaction between shallow soil and structure. For risk assessment, all of these stages are important; however, this paper will focus on the near-surface path through soil and surficial rock. This segment of the problem is commonly called site response analysis. It normally involves estimating an input motion at "bedrock" and computing the resulting surface ground motion (fig. 1, step 3).

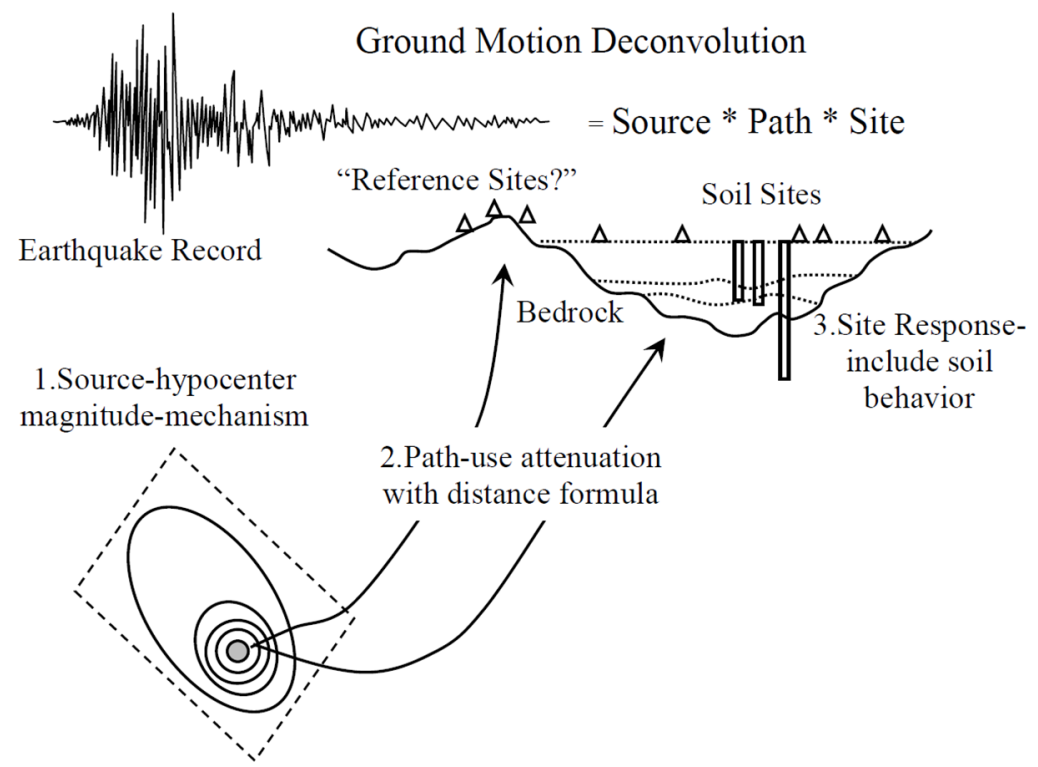

Figure 1: Path of seismic energy toward site (adapted from [1]).

The main parameters involved in the analysis are the intensity and duration of the input base motion and the dynamic properties of the soil layers leading up to the surface. Prior to the analysis the measurement of dynamic soil properties, mainly shear wave velocity in the soil profile is needed. Eurocode [2] simplifies the process by using a simplified profile of the upper $30 \mathrm{~m}\left(v_{s, 30}\right)$. However, to gain a better understanding of response, other soil properties, and a method to select appropriate input base motions are still necessary.

Simplifications to site response analysis often reduce the problem to 1-dimension and a single type of wave: a horizontally-polarized verticallypropagating shear wave. This corresponds to the most potentially damaging wave for buildings. The horizontal motion imparts lateral inertia loads on the building which are generally more difficult to resist than vertical loads. The vertical propagation is a reasonable approximation as well since the pathway for seismic waves becomes more vertical as it moves through material that is less stiff (lower $\left.v_{s}\right)$ as it propagates toward the surface. 


\section{Soil profiles determined for the city of Győr}

The stiffness of the soil at a site has a strong effect on the intensity of shaking delivered to the buildings at the surface. Variability in stiffness contributes to the large differences in ground motions over relatively short distances within sedimentary basins. Site effect studies are connected with the geodynamic characterization of the shallow layers, and can be grouped into three main categories [3]: experimental, numerical and empirical. In the absence of macroseismic data, several methods can be used for obtaining information about the soil response in an area of study. One alternative to determine the effects of soil layers is to use the values of $v_{s, 30}$, the equivalent shear wave velocity that is the weighted average of shear wave velocities in the upper 30 meters.

The geological map series of the Little Hungarian Plain offer a broad view about the formation and lithology of the area. Data concerning Györ can be found on two sets of maps called Györ North and Györ South. The maps were determined from shallow borings (10 m deep) with a raster of approx.1,000-1,500 m, a few small depth borings (30-40 m deep) and one middle deep borings (with $400 \mathrm{~m}$ depth) for each set of maps [4]. The number of borings for the entire territory of Györ is about 28 shallow, and 6 small depth. The geological map series did offer a good overview about the wider area of Györ and the connections to the vicinity and the formation of sediments from different ages. The thickness of quaternary deposits ranges between 10 and $50 \mathrm{~m}$ in Györ, at southern part it decreases to 5$10 \mathrm{~m}$. The basement of Pannonian deposits is between 3,000 and 5,000 m.

To increase the density of data and enhance the accuracy of soil profiles data from the hydrogeological registers were used with the permission of the North Transdanubian Environmental Protection and Water Management Inspectorate. On the territory of the investigated area, around 100 borings were available, from that the 60 chosen hydrogeological registers originated from 1954 to 2008, with a depth varying between 25 and $2,155.7 \mathrm{~m}$. The principle of selection was to cover adequately the study area with borings deeper than $30 \mathrm{~m}$.

The next step was to identify the dynamic properties of the different soil types. During the research, Multichannel Analysis of Surface Waves was performed at 11 places close to the original borings of the hydrogeological registers. Compared to conventional borehole sounding tests, it is less expensive and provides the subsurface shear wave velocity profile over a large area. At four locations, raw data from Cone Penetration Tests were offered by geotechnical companies, which ensured verification of the results. For the completed depth of CPT, average shearwave velocities were calculated and compared to the average shear-wave velocities obtained from MASW measurements for the same depth. Predictive equations were defined by finding a regression for each MASW measured $v_{S}$ profile.

Calculations of $v_{s, 30}$ for each 60 borings were performed, based on three different methods: first using the determined $v_{s}$ intervals for each soil type based on MASW measurements, then applying the values of predictive equations, finally with the help of Hardin and Black's formula [5]. Based on shear wave profiles 15 zones (SPI to SPXV) were determined in Győr. 


\section{Strong motion selection based on REXEL software}

The method chosen to select base motions was a magnitude scaling technique implemented in the software package REXEL [6]. Strong motion records are selected from a database (European Strong-Motion Database, ESD [7]) and compared to a desired set of criteria. If the record meets the criteria it is copied into a "bin" of motions that will be used later. For many typical low to moderate seismic actions, the database will contain many suitable records. However, if the criteria are not met, REXEL will scale the earthquake motion (increase or decrease acceleration amplitude) so that it will meet the criteria. Other parameters affect the suitability of an earthquake for scaling and relocation. Distance from epicentre, frequency content, and type of faulting that initiated the motion all have an impact on the final behaviour in the response analysis.

REXEL evaluates these parameters by asking the user for appropriate degrees of variation in these parameters and searches out those records that will meet these criteria. Naturally, as the criteria become less rigorous, more records (scaled and shifted in frequency or time) will meet the criteria. The most common set of criteria are those described by Eurocode 8 or other building code standards. Design spectra from these codes are easily input to the program and default values of allowed variability are often enough to produce a bin of 7 earthquake records that are subsequently used in the soil response analysis program.

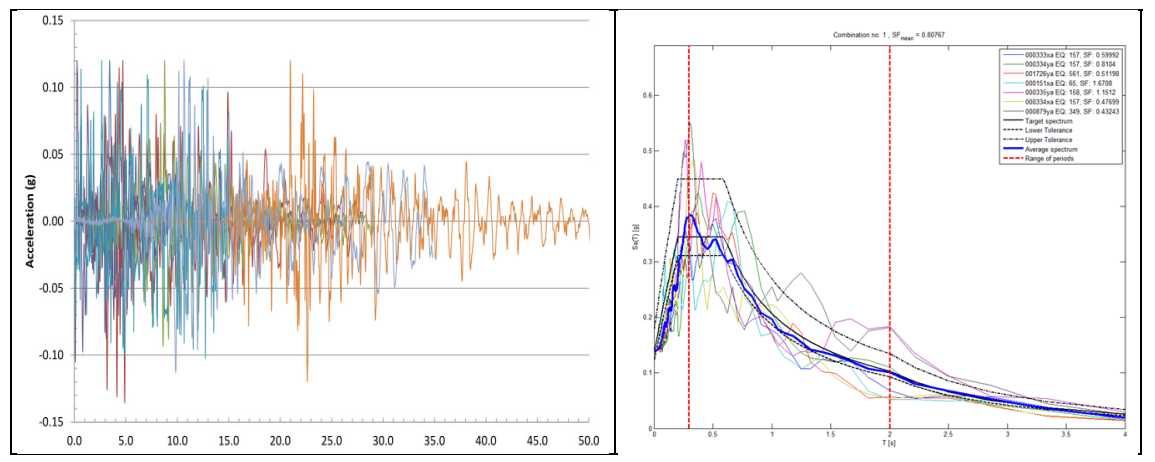

Figure 2: Collection of 7 scaled time histories for site response analysis. Spectra on the right compared to EC-8 Type1 [2].

Earthquake records were selected for site class A, for both EC 8 Type 1 and 2 spectra. The varied parameters were the intensity (M 3-4, 4-5, 5-6, 6-7) and epicentral distance $(0-50,0-100 \mathrm{~km})$ of the earthquakes. Fig. 2 illustrates the set of 7 earthquake records from European Strong-Motion Database [7] and their match to the selected Eurocode 8 Type 1 spectrum in case of site class A, $0.12 \mathrm{~g}$ PGA [8], magnitude values ranging between 5 and 6, and epicentral distance between 0 and $100 \mathrm{~km}$. These values reflect the anticipated seismic event in and around Győr, Hungary [9]. 


\section{Effect of soil profile on surface response}

The next step in the response analysis is to determine the effect of the soil profile on surface response. Several software packages will compute this response, the program STRATA [10] was used in this study due to its ease of use, allowance for many realizations of soil profiles, and low cost (freely available with user manual and sample problems). The numerical approach is very similar to SHAKE [11].

\begin{tabular}{|lll|l}
\hline 1 & $A_{1} \uparrow \nmid B_{1}$ & $\rho_{1} h_{1} G_{1} D_{1}$ \\
\hline 2 & $A_{2} \uparrow \nmid B_{2}$ & $\rho_{2} h_{2} G_{2} D_{2}$ \\
\hline &
\end{tabular} \mid

Figure 3: Complex-valued wave propagation (Shake, Strata) and Discrete Element Time History Models (DeepSoil, Nera) (adapted from [10, $12,13])$.

An excellent summary was given by Kwok et al. [12] concerning the application and evaluation of 1-dimensional site response models. Typical representations of those models are shown in fig. 2(a), (b) for frequency domain approaches such as SHAKE [11] and time domain methods such as DeepSoil [13] using lumped or consistent mass. Frequency domain equivalent linear models are easy to implement and can perform calculations quickly.

For a layered system, shown in fig. 3(a), the wave amplitudes are calculated by maintaining compatibility of displacement and shear stress at the layer boundaries, based on recursive formulas developed by Kramer [15]. The dynamic properties of soil (shear modulus $G$, and damping ratio $D$ ) vary with shear strain, and thus the intensity of shaking. In equivalent-linear site response analysis, the nonlinear response of the soil is approximated by modifying the linear elastic properties of the soil based on the induced strain level, and are iteratively calculated based on the computed strain [10]. The earthquake records are processed via FFT to act as harmonic oscillations. Since the analysis is linear, superposition allows for each harmonic to be solved, then "stacked" together. Inverse FFT produces acceleration, velocity and displacement histories as well as shearing stress and strain vs. time. Solution of the harmonic equations are very fast and many of the higher frequencies $(>30 \mathrm{~Hz})$ can be ignored for many studies.

With the help of response analysis a large number of soil profiles, earthquakes and soil nonlinear conditions can be examined. Soil profiles can be varied by specifying mean and standard deviation values for each soil layer. The impact of the variability of input data on site response can be quantified. 


\section{Site response based on STRATA software}

Response analysis was performed in case of each previously defined 15 soil profiles for Győr taking into account different PGA values according to different Limit Stages. Selected earthquake records were imported to STRATA [10] from European Strong-Motion Database [7] according to REXEL [6] selections. The motion location input was defined in bedrock, using a scale factor for each record to obtain same PGA values.

Method of analysis is based on equivalent linear method, using time series approach. The nonlinear properties of the soil, and site profile were taken into account, reaching 100 realizations in each case. Soil properties were defined based on tables used for design. $G / G_{\max }$ model and damping model of Vucetic and Dobry [15] was used (Table 1).

Table 1: Applied soil properties for examination in Győr.

\begin{tabular}{|c|c|c|c|c|c|c|}
\hline & Name & Unit Weight $\left(\mathrm{kN} / \mathrm{m}^{3}\right)$ & G/G_max Model & Damping Model & Notes & Varied \\
\hline 1 & $\mathrm{Gr}$ & 22.00 & Vucetic \& Dobry, PI = 0 & Vucetic \& Dobry, PI = 0 & & $\nabla$ \\
\hline 2 & saGr_grSa & 21.00 & Vucetic \& Dobry, PI = 0 & Vucetic \& Dobry, PI = 0 & & $\nabla$ \\
\hline 3 & Sa & 19.00 & Vucetic \& Dobry, PI = 0 & Vucetic \& Dobry, PI = 0 & & $\nabla$ \\
\hline 4 & $\mathrm{Cl}$ & 20.00 & Vucetic \& Dobry, PI = 30 & Vucetic \& Dobry, PI = 30 & & $\nabla$ \\
\hline 5 & siCl & 19.50 & Vucetic \& Dobry, PI $=15$ & Vucetic \& Dobry, PI = 15 & & $\nabla$ \\
\hline 6 & $\mathrm{saCl}$ & 20.50 & Vucetic \& Dobry, PI = 30 & Vucetic \& Dobry, PI = 30 & & $\nabla$ \\
\hline 7 & Alluvium_Sa (D>30m) & 20.00 & Vucetic \& Dobry, PI = 0 & Vucetic \& Dobry, PI = 0 & & $\nabla$ \\
\hline 8 & Alluvium_grSa_saGr $(\mathrm{D}>30 \mathrm{~m})$ & 22.00 & Vucetic \& Dobry, PI = 0 & Vucetic \& Dobry, PI = 0 & & $\nabla$ \\
\hline 9 & Alluvium_Cl (D>30m) & 21.00 & Vucetic \& Dobry, PI = 30 & Vucetic \& Dobry, PI = 30 & & $\nabla$ \\
\hline 10 & Alluvium_saCl $(\mathrm{D}>30 \mathrm{~m})$ & 21.50 & Vucetic \& Dobry, PI = 30 & Vucetic \& Dobry, PI = 30 & & v \\
\hline 11 & Alluvium_siCl (D>30m) & 20.50 & Vucetic \& Dobry, PI = 15 & Vucetic \& Dobry, PI = 15 & & $\nabla$ \\
\hline 12 & siSa_clSa & 20.00 & Vucetic \& Dobry, PI = 0 & Vucetic \& Dobry, PI = 0 & & $\nabla$ \\
\hline 13 & $\mathrm{Si}$ & 19.50 & Vucetic \& Dobry, PI = 0 & Vucetic \& Dobry, PI = 0 & & $\nabla$ \\
\hline 14 & stiffCl & 21.00 & Vucetic \& Dobry, PI = 30 & Vucetic \& Dobry, PI = 30 & & $\nabla$ \\
\hline 15 & $\mathrm{Cls}$ & 23.00 & Vucetic \& Dobry, PI = 0 & Vucetic \& Dobry, PI = 0 & & $\nabla$ \\
\hline 16 & Ss & 25.00 & Vucetic \& Dobry, PI = 0 & Vucetic \& Dobry, PI = 0 & & $\nabla$ \\
\hline
\end{tabular}

One such set of results from Strata is shown in fig. 4 for 700 analyses performed in Györ [9]. The realizations were based on 100 variations of soil profiles and properties and 7 different earthquake histories. The mean value and log standard deviations are also shown for comparison. For all realizations the maximum base acceleration is $0.12 \mathrm{~g}$, but variations in soil properties $\left(G, D\right.$ and $\left.G / G_{\max }\right)$ produced the large variations in response.

Different total depths were examined to decide the depth used for response analysis in case of Györ. Fig. 4 presents the differences between a total depth of 
$30 \mathrm{~m}$ (black line), $100 \mathrm{~m}$ and $200 \mathrm{~m}$ (gray line). It is obvious that results of the analysis considering only the upper $30 \mathrm{~m}$ is not appropriate for the purposes of the research. The results of the examinations considering 100 or $200 \mathrm{~m}$ total depth match adequately. The depth of the examined borings ranges between 100 and $200 \mathrm{~m}$, only 13 exceeds $200 \mathrm{~m}$, so the total depth of the examinations were set to $100 \mathrm{~m}$.

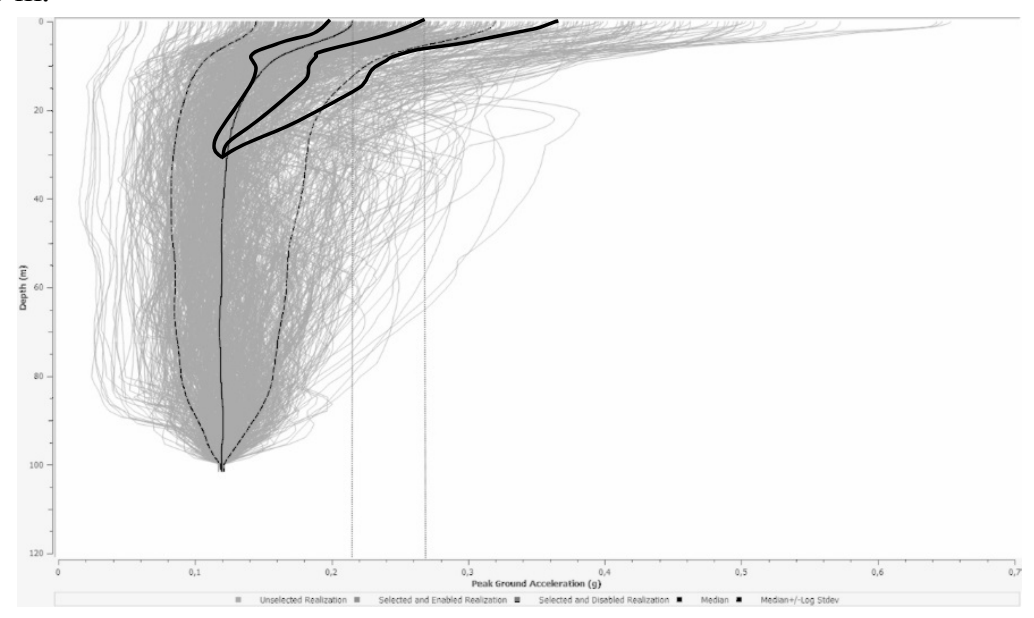

Figure 4: Peak ground acceleration [g] profile vs depth [m].

Peak ground acceleration profiles, spectral acceleration and transfer functions were plotted for each soil profile. Soil amplification was estimated for 15 soil profiles based on response analysis. Table 2 contains the amplification values and the dominant first and second frequencies of the transfer functions for each soil profile for the return period of 475 years.

\section{Hazard compared to Eurocode 8 response spectra}

The site response analysis determines the main frequencies and amplification that the surface of the ground will experience. Site response analysis was performed based on a one dimensional analysis of STRATA software, with an earthquake input motion introduced at bedrock and the waves travelled vertically up through the soil column. Acceleration time histories were generated with help of REXEL software, compatible to Eurocode Type 1 and 2 spectra (T1 and T2). Seven different acceleration time histories for site response analyses were used in case of each soil profile with 100 realizations, varying the soil properties, taking into account different scenarios for different return periods: 225, 475 and 2475 years. Fig. 5 shows the median values and the logarithmic standard deviation of the spectral acceleration for different bins of earthquakes in case of one of the previously-defined soil profiles. In fig. 5(a) the return period is the same for both median values (475 years), but one represents the median values generated from the bin of earthquakes fitting T2 spectra (black lines), and the line shifted to the right represents the median values generated from the bin of earthquakes fitting 
Table 2: PGA median values and standard deviation, and amplification factors [9].

\begin{tabular}{|l|c|c|c|c|c|c|}
\hline \multirow{2}{*}{$\begin{array}{l}\text { Soil } \\
\text { profile }\end{array}$} & \multicolumn{2}{|c|}{ PGA [0.12 g] } & $\begin{array}{c}\text { Amplifi- } \\
\text { cation }\end{array}$ & \multicolumn{3}{c|}{$\begin{array}{c}\text { Data from median values of } \\
\text { transfer function }\end{array}$} \\
\cline { 2 - 7 } & Median & $\begin{array}{c}\text { Log } \\
\text { Stdev }\end{array}$ & $\mathrm{m}$ & $\mathrm{m} 1$ & $\mathrm{f}_{1}[\mathrm{~Hz}]$ & $\mathrm{T}_{1}[\mathrm{~s}]$ \\
\hline I. & 0.192 & 0.447 & 1.601 & 1.570 & 0.652 & 1.533 \\
\hline II. & 0.214 & 0.374 & 1.782 & 1.937 & 0.767 & 1.304 \\
\hline III. & 0.234 & 0.413 & 1.949 & 1.714 & 0.915 & 1.093 \\
\hline IV. & 0.199 & 0.363 & 1.660 & 1.806 & 0.727 & 1.376 \\
\hline V. & 0.206 & 0.440 & 1.715 & 1.499 & 0.717 & 1.395 \\
\hline VI. & 0.197 & 0.462 & 1.642 & 1.610 & 0.644 & 1.554 \\
\hline VII. & 0.216 & 0.492 & 1.797 & 1.591 & 0.843 & 1.186 \\
\hline VIII. & 0.212 & 0.437 & 1.768 & 1.680 & 0.757 & 1.321 \\
\hline IX. & 0.210 & 0.419 & 1.754 & 1.599 & 0.788 & 1.269 \\
\hline X. & 0.191 & 0.405 & 1.595 & 1.729 & 0.727 & 1.376 \\
\hline XI. & 0.197 & 0.378 & 1.639 & 1.711 & 0.727 & 1.376 \\
\hline XII. & 0.211 & 0.457 & 1.761 & 1.618 & 0.799 & 1.252 \\
\hline XIII. & 0.322 & 0.452 & 2.680 & 1.879 & 1.231 & 0.812 \\
\hline XIV. & 0.296 & 0.416 & 2.471 & 1.660 & 1.019 & 0.981 \\
\hline XV. & 0.243 & 0.535 & 2.029 & 1.433 & 0.832 & 1.202 \\
\hline
\end{tabular}

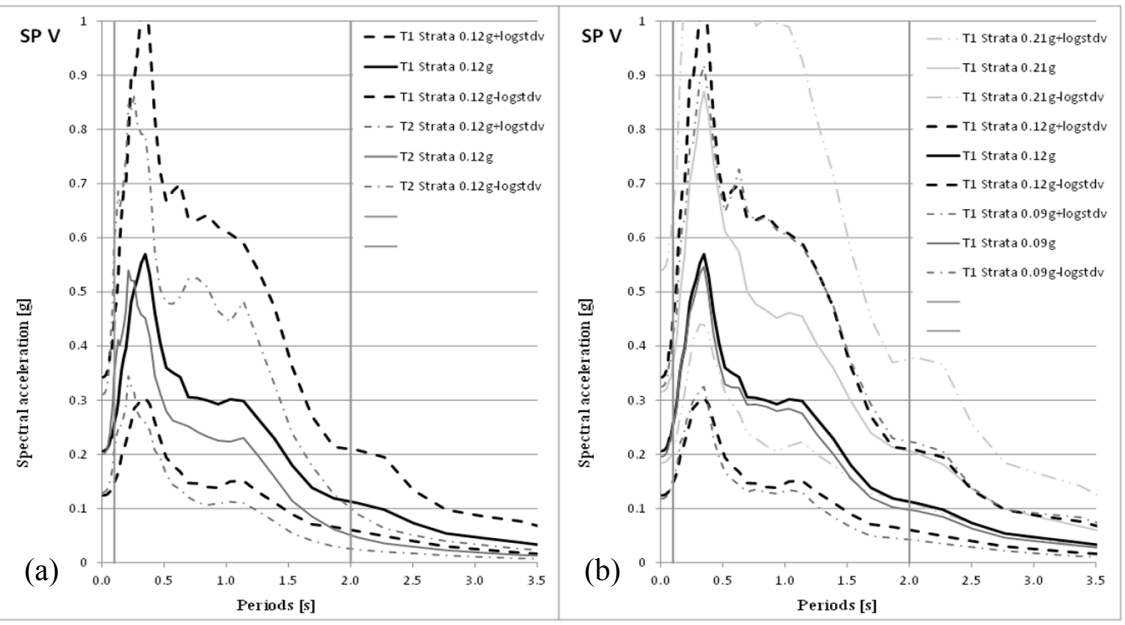

Figure 5: Spectral acceleration results for one soil profile.

T1 spectra. These median lines are very close to each other in case of every soil profiles, the two lines almost overlap each other, only a little shift to the right can be observed in case of spectral acceleration calculated based on T1 compatible earthquake bin (gray lines).

Results of acceleration spectra for different return periods can be seen for soil class $\mathrm{C}$ on the fig. 5(b). In the case of 225 years return period the median values of the acceleration spectra are almost as high as the median values of the acceleration spectra obtained for 475 years return period. The local deposits 
amplify more the outcrop acceleration resulting from minor earthquakes, than in case of higher intensities. Buildings should be controlled in case of Limit State of Damage Limitation assuming 225 years return period, corresponding to a probability of exceedance of $20 \%$ in 50 years according to Eurocode 8 . That means that these buildings should remain in operational state, but they were designed against seismic loads assuming 475 years return period referred to Limit State of Significant Damage.

In fig. 6(a) and (b) are presented the compared results of the median values of spectral acceleration obtained from the bin of earthquakes fitting code-based T1 and T2 spectra respectively. The code-spectra do not cover the expected values of the acceleration spectra obtained from one dimensional site response analysis. The peak values are much higher than the plateau of both code spectra, even considering acceptable risk, especially in the first case. Buildings with frequency range between $1.33 \mathrm{~Hz}$ and $0.8 \mathrm{~Hz}$ (period between 0.75 and $1.25 \mathrm{~s}$ ) designed due to EC8 in Györ might be designed underestimating the actual earthquake forces. This second "bump" on each diagram should be considered to be a result of the second dominant frequency shown on transfer functions specific to almost all soil profiles in Györ. The range of periods (frequencies) where the bump occurs represent response common to a 7-storey $\mathrm{RC}$ frame building [16]. Spectral acceleration is different for buildings with different importance factors. Buildings are classified in 4 importance classes, depending on the consequences of collapse for human life, on their importance, and on the social and economic consequences of collapse.

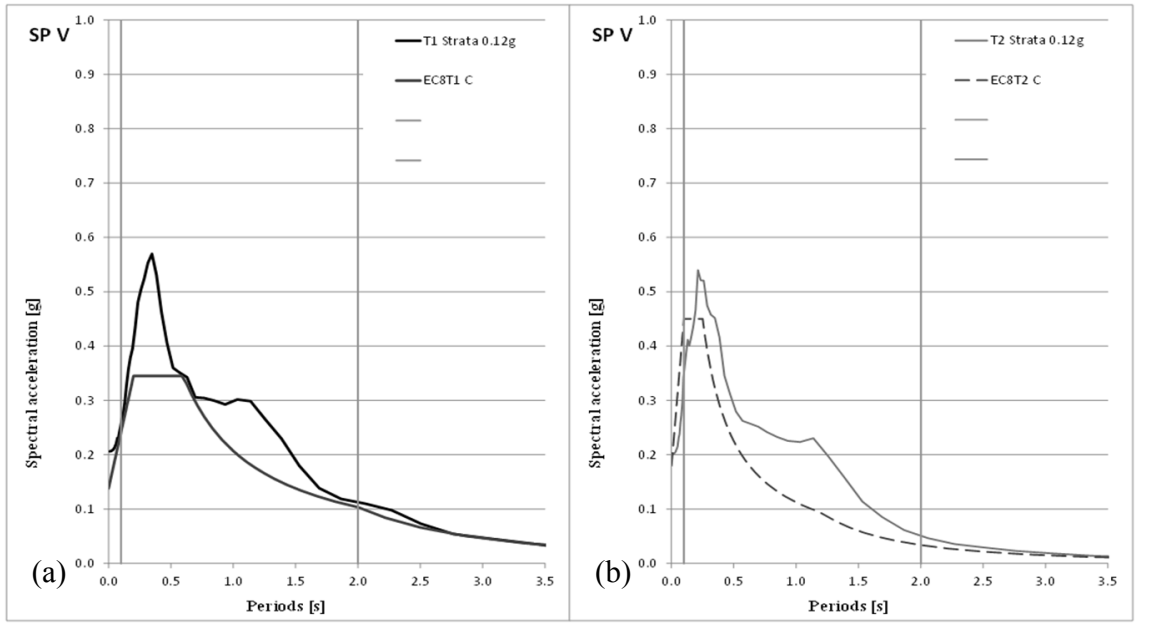

Figure 6: Spectral acceleration results compared to acceleration spectra of EC8 (T1 and T2).

During the analysis of local site effects the results were compared to different levels of safety due to importance classes and importance factors according to EC8. Different level of safety represented with different response spectra taking into account importance factor II, III and IV respectively, can be seen in fig. 7(a). 
The figure shows that not even the buildings with highest importance factor (1.4) meet the expected median values (without importance factor) of spectral acceleration specific to the site. The plots shown here point out the importance of understanding local site response. Effects of layered soils that do not conform to code profiles can produce significant amplification of seismic actions.

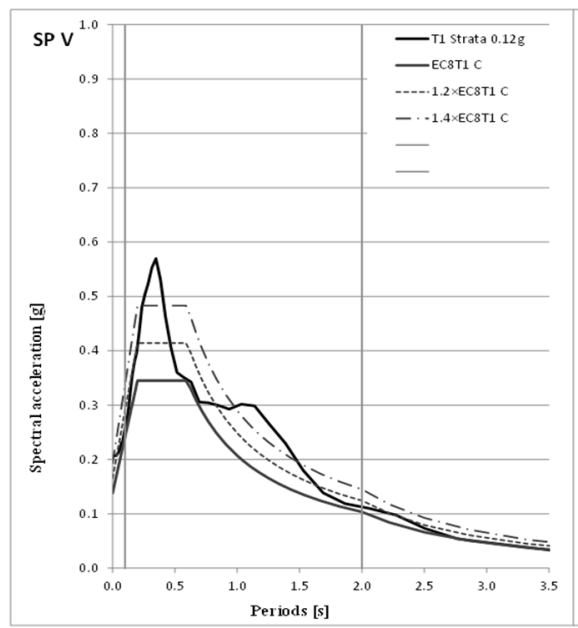

(a)

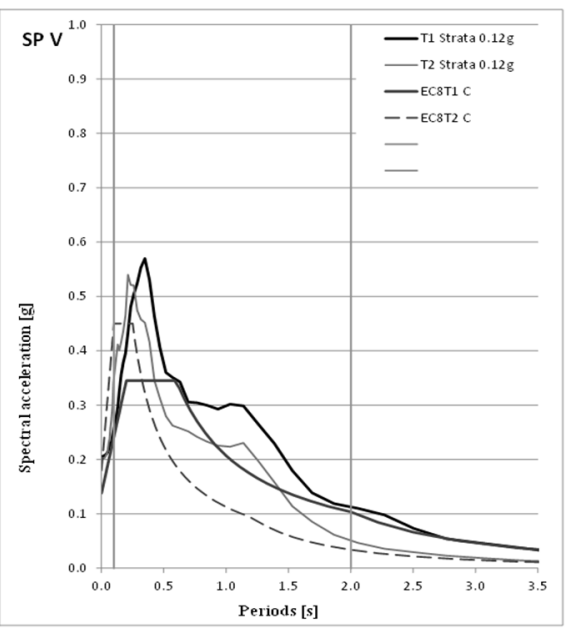

(b)

Figure 7: Spectral acceleration results compared to different acceleration spectra of EC8.

Logarithmic standard deviation in fig. 5 highlights that the variability of actions is very large for even fairly simple soil profiles and "typical" earthquake records. It is for these two observations that the engineer should be cautious in selecting a single number for PHA and applying it blindly to every analysis.

\section{Recommendations}

Even a simple 1D response analysis demonstrates the highly variable nature of earthquake actions and behavior. This variability is difficult to capture in simple code spectra and design engineers are cautioned to consider the impacts of simplification on their design. By varying soil properties and base accelerations, large differences in averaged response are possible. Quantifying the impact of variations to the average then becomes an even greater challenge. The authors are presently studying different ways to account for the widely variable response results shown here. Representing behavior through probabilistic approaches is one option. However, even probabilistic approaches can quickly become numerically intractable when studying the building stock of an entire city distributed over many distinct zones of seismic action.

Further response analyses will be performed including 2D and 3D approaches where soil, topographic, and building conditions warrant the added modeling effort. Further research will also be focused on methods to quantify the level of 
disagreement between code spectra and response analysis results to see what the impact of variability is on the eventual risk levels within the city. Developing more "customized" spectra for the city is also possible, but further study of building response and vulnerability would be a prudent first step. Additionally, from the viewpoint of the city or county engineer, the need to define a workflow for such work is equally important since limited time and workforce resources will have an impact on the ability to clearly define seismic actions within a study area.

\section{Conclusion}

This study presents a part of the seismic risk assessment in a small city. The area is considered a moderate earthquake risk with past events estimated up to $M=6.5$. It is a typical situation for many cities in Hungary and throughout Europe where the seismic hazard is not great, but cannot be ignored. In order to make the best use of limited resources, this methodology used existing soil data, a limited number of field tests and free, but sophisticated software.

One alternative to determine the effects of soil layers is to use the values of $v_{s, 30}$, the equivalent shear wave velocity that is the weighted average of shear wave velocities in the upper 30 meters. Based on shear wave profiles 15 zones were determined in Györ. The basic intention in assessing the ground shaking intensity is to estimate the effects of local site conditions. This decision should be made on all the available results from site identifications from average of shear wave velocity to results of site response analysis. The main objective is to estimate more accurately the ground motion characteristics during possible earthquakes taking into account all the main controlling factors. Variation in seismic hazard was evaluated mainly as a function of soil type. Starting with historical soil data, field testing by MASW was performed in strategic locations. Based on the results and correlations with the historical data, soil profile zones were delineated through the city. Using 1-dimensional site response software with 6,000 realizations, the impact of the different soil zones was evaluated and compared to the more uniform approach by soil type profile from Eurocode 8 . While there was very general agreement with EC-8, there was also a great deal of variation in the level of seismic action due to the different soil profiles. The results of site response analysis reveals the fact, that in areas with diverse soil conditions, especially in case of alluvium further analysis is needed for creating elastic response spectrum for design purposes.

The results can be applied in further risk studies, it is a public safety issue that requires appropriate risk management measures and means to protect citizens, properties, infrastructures and the built cultural heritage. The aim of a seismic risk analysis is the estimation and the hypothetical, quantitative description of the consequences of seismic events of an investigated area, on a regional or state level.

\section{Acknowledgements}

Data processing of the research concerning seismic risk assessment of Györ was supported by the European Union and the State of Hungary, co-financed by the 
European Social Fund in the framework of TÁMOP 4.2.4. A/2-11-1-2012-0001 'National Excellence Program'.

\section{References}

[1] Boore, D. M. Can Site Response Be Predicted? Journal of Earthquake Engineering, Vol. 8, Special Issue 1, pp. 1-41. 2004

[2] European Committee for Standardization: Eurocode 8: Design of Sturctures for Earthquake Resistance MSZ EN 1998-1:2004/A1:2013. Brussels. 2013

[3] Bard, P.-Y. \& Gariel, J.-C. The Seismic Response of Two-dimensional Sedimentary Deposits with Large Vertical Velocity Gradients. Seismological Society of America, Vol. 76 No. 2, pp. 343-366. 1986

[4] Scharek, P. \& Tóth, G. Geological and Hydrogeological Analysis of the Natural Reservation Areas, Budapest: Magyar Állami Földtani Int. 1994

[5] Hardin, B. O. \& Black, W. L. Vibration Mod. of Norm. Consolidated Clay. Jour. Soil Mech. \& Found. Div., ASCE, Vol 95. No. 2, pp. 353-369. 1968

[6] Iervolino, I., Galasso, C. \& Cosenza, E. Comp. Aided Record Selection for Code-based Seis. Struc. Anal.. Bull. of Eq. Eng., Vol. 8, pp. 339-362. 2010

[7] Ambraseys, N. et al. Internet-Site for European Strong-Motion Data, Eu. Com. Research-Dir. http://www.isesd.hi.is/ESD Local/frameset.htm 2002

[8] GeoRisk Earthquake Engineering Ltd. Seismic Hazard Map of Hungary. http://georisk.hu/. 2006

[9] Kegyes-Brassai O. K. Eq. Hazard Analysis and Building Vulnerability Assessment to Determine the Seismic Risk of Existing Buildings in an Urban Area, PhD diss. Széchenyi Univ., Győr, Hungary, 199 p. 2015

[10] Kottke, A. \& Rathje, E. M. NEEShub - Resources: Strata https://nees.org/ resources/strata. 2013

[11] Schnabel, P. B., Lysmer, J. and Seed, H. Bolton SHAKE: A Comp. Prog. for Eq. Response Analysis of Horizontally Layered Sites, Rep. No. UCB/EERC72112, EERC, Univ. of California, Berkeley, December, 102 p. 1972

[12] Kwok, A. O. L. et al. Use of exact solutions of wave propagation problems to guide implem. of nonlin., time-domain ground response analysis routines. ASCE Jour. Geotech. \& Geoenv. Eng. 133(11), pp. 1337-1481. 2007

[13] Hashash, Y.M.A. \& Park, D. Visc. damping formulation and high-frequency comp. in deep deposits. Soil Dyn. \& Eq. Eng., v. 22 (7), pp. 611-624. 2002

[14] Bardet, J. P. \& Tobita, T. NERA: A Computer Program for Nonlinear Earthquake site Response Analyses of Layered Soil Deposits. Dep. of Civil Eng., Univ. of Southern California, Los Angeles, United State, 43 p. 2001

[15] Kramer, S. L. Geotechnical Earthqauke Engineering. Upper Saddle River, New Jersey: Prentice Hall. 1996

[16] Ray, R.P. \& Wolf, A. Analysis and Design of Piles for Dynamic Loading in: P. Delage et al. eds. Proc. $18^{\text {th }}$ Int. Conf. on Soil Mech. \& Geotech. Eng.: Challenges and Innovations in Geotechnics. Paris, pp. 2839-2842. 